\title{
Buckling of Cracked Laminated Composite Cylindrical Shells Subjected to Combined Loading
}

\section{Hamidreza Allahbakhsh \& Mahmoud Shariati}

\section{Applied Composite Materials}

An International Journal for the Science and Application of Composite Materials

ISSN 0929-189X

Appl Compos Mater

DOI 10.1007/s10443-012-9300-9
Volume 19 No. 5 October 2012

ISSN 092

Applied Composite Materials

An International Journal for the Science and Application of Composite Materials

Editor-in-Chief

Peter W.R. Beaumont

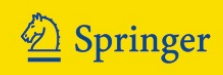

ONLINE FIRST

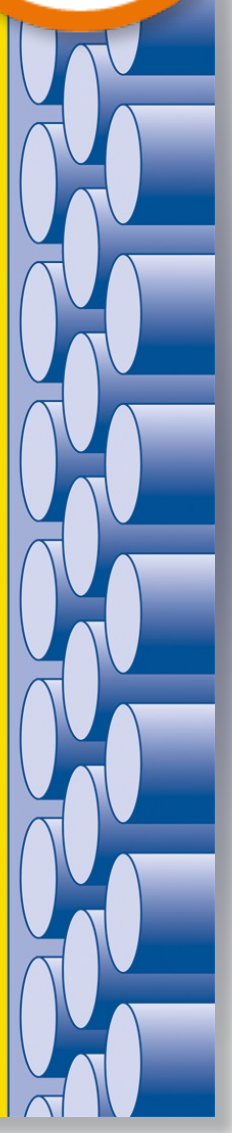

包 Springer 
Your article is protected by copyright and all rights are held exclusively by Springer Science +Business Media Dordrecht. This e-offprint is for personal use only and shall not be selfarchived in electronic repositories. If you wish to self-archive your work, please use the accepted author's version for posting to your own website or your institution's repository. You may further deposit the accepted author's version on a funder's repository at a funder's request, provided it is not made publicly available until 12 months after publication. 


\title{
Buckling of Cracked Laminated Composite Cylindrical Shells Subjected to Combined Loading
}

\author{
Hamidreza Allahbakhsh • Mahmoud Shariati
}

Received: 12 August 2012 / Accepted: 25 October 2012

(C) Springer Science+Business Media Dordrecht 2012

\begin{abstract}
A series of finite element analysis on the cracked composite cylindrical shells under combined loading is carried out to study the effect of loading condition, crack size and orientation on the buckling behavior of laminated composite cylindrical shells. The interaction buckling curves of cracked laminated composite cylinders subject to different combinations of axial compression, bending, internal pressure and external pressure are obtained, using the finite element method. Results show that the internal pressure increases the critical buckling load of the CFRP cylindrical shells and bending and external pressure decrease it. Numerical analysis show that axial crack has the most detrimental effect on the buckling load of a cylindrical shell and results show that for lower values of the axial compressive load and higher values of the external pressure, the buckling is usually in the global mode and for higher values of axial compressive load and lower levels of external pressure the buckling mode is mostly in the local mode.
\end{abstract}

Keywords Crack $\cdot$ Laminated cylindrical shells $\cdot$ Buckling analysis $\cdot$ Internal and external pressure $\cdot$ Axial compression $\cdot$ Bending moment

\section{Introduction}

Laminated composite shells are widely used in aerospace structures, automobile industry, civil, marine and other engineering structures. Presence of defects, such as cracks and cutout, may seriously compromise their buckling behavior and jeopardize the structural integrity [1, 2]. Comprehensive understanding of the buckling response of laminated composite cylindrical shells is necessary to assure the integrity of these shells during their service life. Different studies have focused on designing optimum composite shells for enhancing the

H. Allahbakhsh $(\bowtie)$

Mechanical Department, Islamic Azad University, Shahrood Branch, Daneshgah Boulevard, Shahrood, Iran

e-mail: allahbakhshy@gmail.com

M. Shariati

Mechanical Department, Shahrood University of Technology, Shahrood, Iran 
strength under various loading conditions such as pure axial compression [3-5], combined axial compression and torsion [6-8], transverse load [9] and combined axial compression and pressure $[10,11]$.

Composite cylindrical shells are often subjected to defects and damage from both in-service and manufacturing events. Presence of defects such as cracks is the most important of these defects. Presence of cracks could strongly affect the buckling response of shells not only by decreasing their load carrying capacity but also by introducing local buckling at the crack region [10, 11].

Vaziri and Estekanchi [10] studied the effect of crack size, type and orientation on the buckling behavior of cylindrical shells under combined internal pressure and axial compression. They investigated two types of crack; through crack and thumbnail crack. The internal pressure may stabilize the shell against local buckling by suppressing the lower modes associated with local buckling or may provoke the local buckling of cylindrical shells due to stress concentration. In another work, Vaziri [12] studied the effect of crack size and orientation, as well as the composite ply angle on the buckling response of cylindrical shells under axial compression. The results indicated that the composite ply angle can be chosen to minimize the potential sensitivity of composite cylindrical shell to the presence of a crack. In an earlier paper, Jahromi [13] presented linear eigenvalue buckling analysis for doubly and singly cracked cylindrical shells subjected to axial compression using the finite element method. Results indicated that For cylinders with two cracks, the buckling behavior is influenced not only by the buckling behavior of each individual crack but also by the interaction between the cracks.

The analysis of cracked shells have often been investigated numerically, since numerical simulation makes it possible to probe the behavior over an extensive range of loading conditions and geometrical parameters. The computational models of cracked cylinders were developed by extending a special plane stress crack tip meshing scheme proposed by Estekanchi and Vafai [3]. In this approach, the size of the element decreases incrementally from the constant element size employed in the uncracked region by approaching the crack tip. This meshing scheme makes easier the generation of computational models of cracked shells and thus, allows the large number of parametric investigations on the mechanical response of cracked shells. This method has been previously used to study the buckling behavior of cracked plates $[14,15]$ and cylinders subjected to tension or compression $[12,16]$, pure torsion [17] and combined axial compression and internal pressure [10].

An alternative meshing scheme is based on progressive change of the element orientation at each zoom level. This method is shown to be more accurate for fracture mechanics analysis, while the former scheme is capable of capturing the main features of local buckling and deformation of cracked cylindrical shells with a remarkable accuracy [11].

However the relatively large attention given to the buckling analysis of cracked cylindrical shells, there is scarcely any study available on the effect of crack in a laminated composite cylindrical shell subjected to combined loading. Most of the published data investigates the buckling behavior of compression-loaded cracked laminated composite shells. In spite of this, the works of Tafreshi [18, 19] on the effects of delamination on the stability of cylinderical composite shells under combined loading must also be cited.

This paper studies the buckling of cracked composite cylindrical shells subject to axial compression, bending moment, internal and external pressure in different combination. The 
interactive buckling curves of a cracked composite cylindrical shell subject to various combinations of these different types of loadings are obtained. Whenever possible, the buckling loads are compared with corresponding experimental or numerical studies presented in literature.

\section{Buckling Analysis Using the Finite Element Method}

In this paper, we used the meshing approach proposed by Estekanchi and Vafai [3] for constructing the shell elements close to the crack tip. Figure 1 shows an example of the developed finite element mesh based on this meshing scheme. The nonlinear element S8R, which is an eight-node element with six degrees of freedom per node and quadratic deformation shape in both in-plane directions, is used in the computational models.

The finite element model includes 40 elements in longitudinal and 63 elements in circumferential directions. In the crack region, the size is of the element decreased to 0.5 of its primary size with 5 level of rising which results in crack tip element size of $1 / 32$ of those used in the uncracked region. This is the optimal number of elements after the conduction of the mesh convergence study.

The simulations were carried out using Abaqus finite element package. The validity of this method for investigation the buckling behaviour of cracked cylindrical shells is established in previous study by authors [20] and Figs. 2 and 3 as well.

Simitses et al. [21] carried out the buckling analysis of metallic and laminated cylindrical shell under combined bending and axial compression, using the finite element analysis. In their paper, they have presented critical loads of composite cylindrical shell under combined bending and compressive loads. Figure 4 depicts the interactive buckling curves, axial compression vs bending curve, produced by Simitses et al. in Ref. [21] and FE results by Tafreshi [19]. In Fig. 4 the FE results of the present study have been compared with the corresponding experimental results and FE results by Tafreshi [19] as well. Figure 4 depicts the interactive buckling curves

a

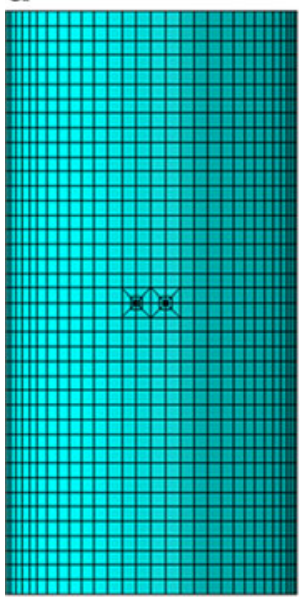

b

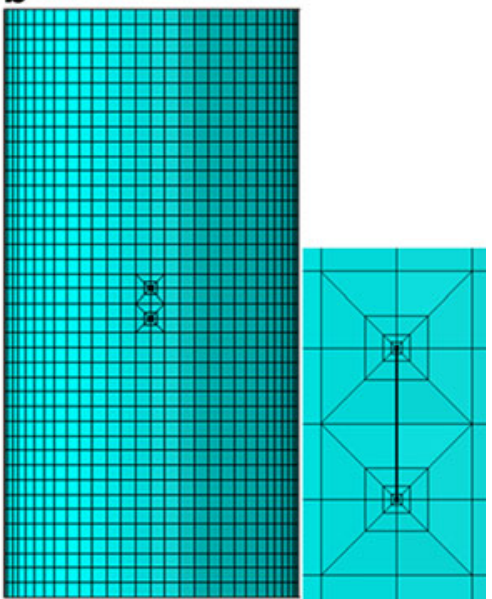

Fig. 1 Finite element model of cylindrical shells with a a circumferential crack and $\mathbf{b}$ an axial crack 
Fig. 2 Comparisons of buckling curves for cracked cylindrical shells under axial compression

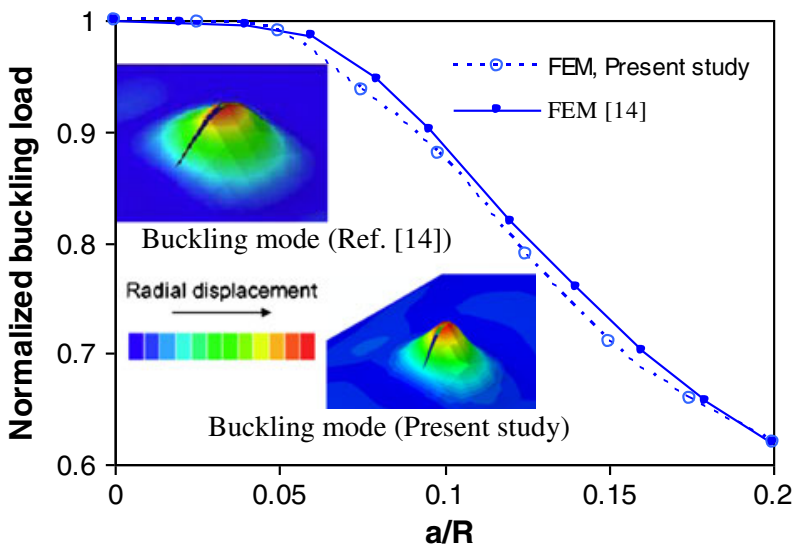

for a boron-epoxy cylindrical shell $(\mathrm{L} / \mathrm{r}=1$ and $\mathrm{r} / \mathrm{t}=354)$ with the stacking sequence of [45/-45] used by Simitses et al. and also the buckling curve obtained in this study. It can be observed that the trends of variation of results are similar.

During this paper the finite element model of the composite cylindrical shell has the length of $L=2 \mathrm{~m}$ and the radius of $\mathrm{R}=0.5 \mathrm{~m}$. The lamina material properties are as follows: longitudinal compression modulus $\mathrm{E}_{1}=123.55 \mathrm{GPa}$, transverse modulus $\mathrm{E}_{2}=8.707 \mathrm{GPa}$, in-plane shear modulus $\mathrm{G}_{12}=5.695 \mathrm{GPa}$, and major Poisson's ratio $v=0.31$ (representing Carbon fibre reinforced polymer [8]). The ply thickness of the composite is $0.125 \mathrm{~mm}$ with the laminate stacking of $[0 / 0 / 90 / \pm 45 / \mp 45 / 90 / 0 / 0]_{2}$.

In this paper the interaction buckling curves of the cracked composite cylindrical shell with Carbon fibre reinforced polymer (CFRP) material properties and stacking sequence of $[0 / 0 / 90 / \pm 45 / \mp 45 / 90 / 0 / 0]_{2}$ for axial compression $\left(R / R_{c}\right)$ vs bending $\left(M / M_{c}\right)$, at different pressure $(\mathrm{P} / \mathrm{Pc})$ are obtained. Figure 5 depicts a typical cylindrical shell subjected to bending moment with angle of $\theta, \mathrm{M}_{(\theta)}$. During this paper, the internal pressure is assumed to be negative and the external pressure is assumed to be positive. $R_{c}, P_{c}, M_{c}$ and $\mathrm{p}$ are the critical buckling loads when the perfect composite cylindrical shell is subject to pure loading, pure pressure, pure bending and critical buckling load of cracked cylinder under pure pressure, respectively.

Fig. 3 Comparisons of buckling curves for cracked cylindrical shells under combined loading of axial compression and $344.75 \mathrm{kPa}$ internal pressure

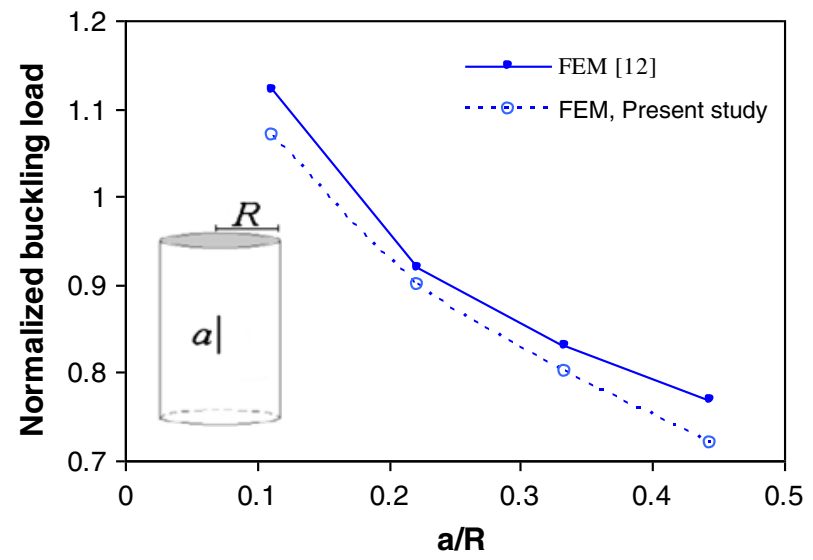


Fig. 4 Interaction buckling curve of boron-epoxy cylindrical shell subject to combined axial compression and bending moment $(\mathrm{L} / \mathrm{r}=1.0, \mathrm{r} / \mathrm{t}=354$, $r=19 \mathrm{~cm},(45 /-45)_{\mathrm{s}}, \mathrm{E}_{1}=$ 18.61 GPa, $\mathrm{E}_{2}=204.71 \mathrm{GPa}$, $\left.v=0.21, \mathrm{G}_{1}=\mathrm{G}_{12}=4.46 \mathrm{GPa}\right)$

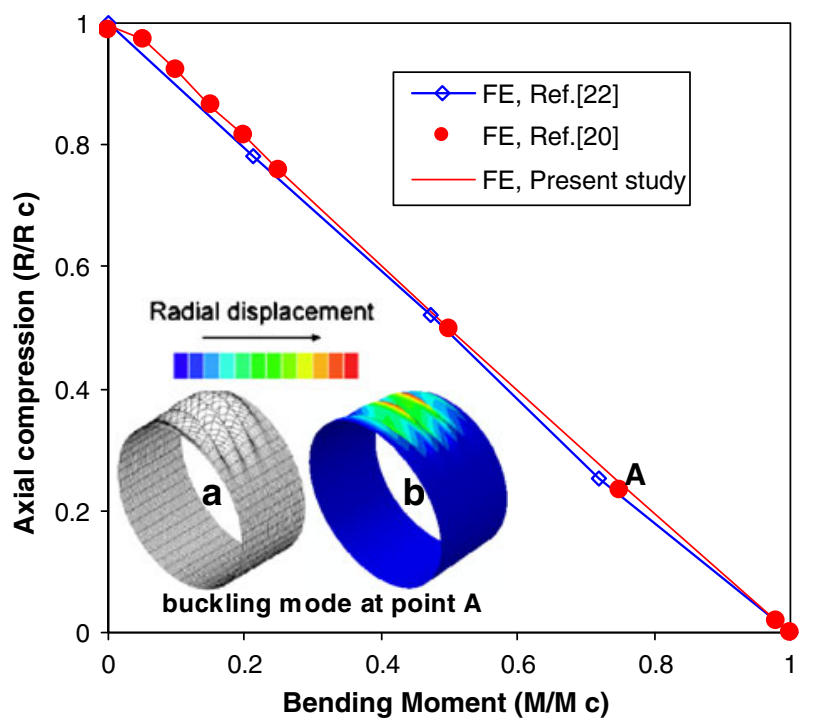

Figure 6(a)-(b) depict the interaction curves, axial compression $\left(R / R_{c}\right)$ vs pressure $\left(\mathrm{P} / \mathrm{P}_{\mathrm{c}}\right)$, at different bending moment $\left(\mathrm{M} / \mathrm{M}_{\mathrm{c}}\right)$. The pressure level varies from $-\mathrm{P}_{\mathrm{c}}$ to $\mathrm{P}_{\mathrm{c}}$. The influence of internal or external pressure is the consequence of interaction of two mechanisms: (a) the stabilizing effect of hoop tension that tends to raise the buckling load of perfect cylindrical shells or cylindrical shells with small geometric imperfections, and (b) the induced local stress at the crack edges, in combination with the local disturbance of the stress field tend to make easier the local buckling. Figure 6 (a)-(b) show that for external pressure of $P<0.7 p$ in each level of bending moment local buckling is observed and critical buckling load decreased slightly as the external pressure increased. Subsequently for external pressure of $P>0.7 p$, the critical buckling curves with circumferential crack decreases considerably. Therefore, it can be deduced that the weakening effect of pressure is the dominant mechanism for cylindrical shells with circumferential crack at external pressure. Figure 6(c) shows three different distributions of buckling deformation mode a cylinder: a) Global: The buckling load and shape are approximately like those of the counterpart uncracked cylindrical shell; b) Transition: In this deformation mode buckling shape is not localized and the crack

Fig. 5 Geometry of the shell model with a crack subjected to bending

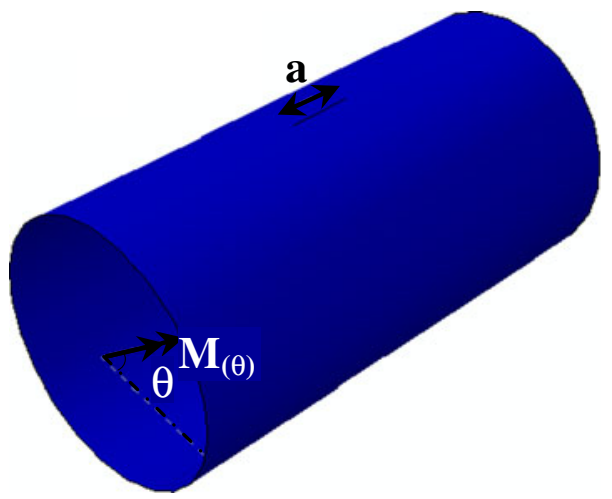


a)

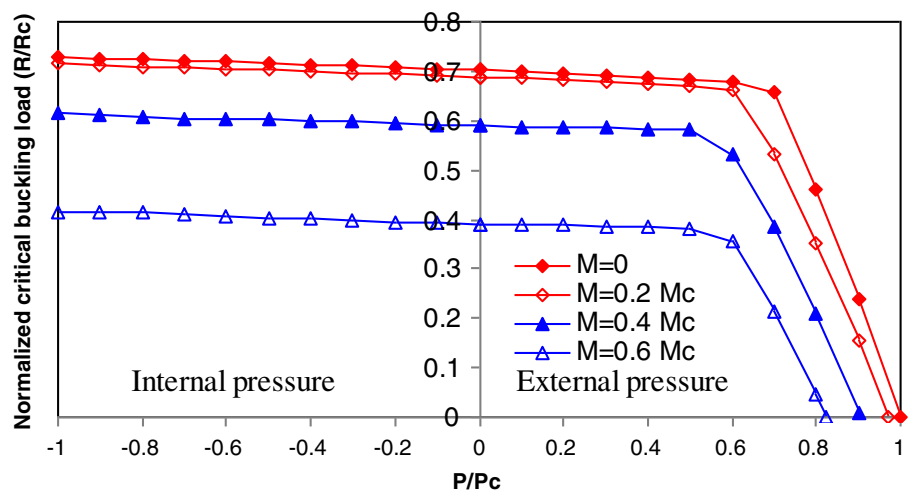

b)

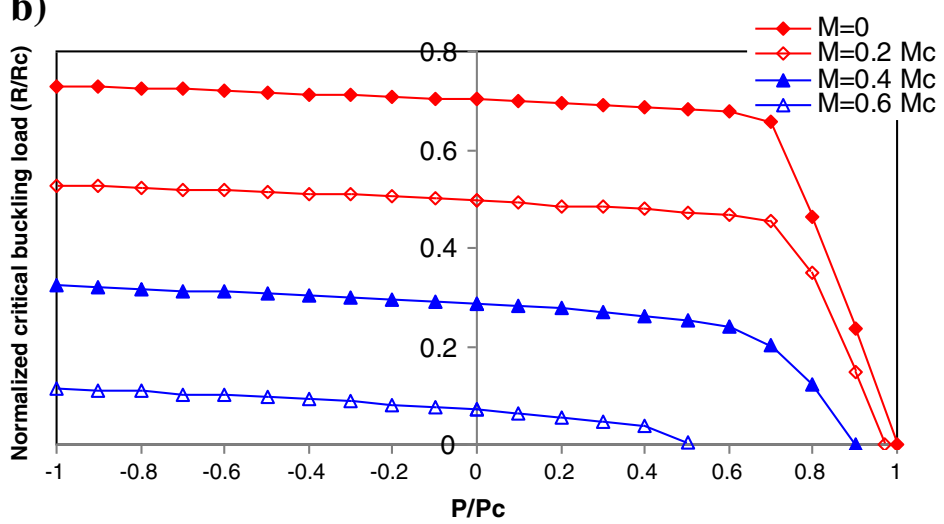

c)

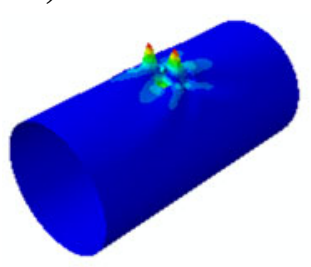

Local buckling shapes

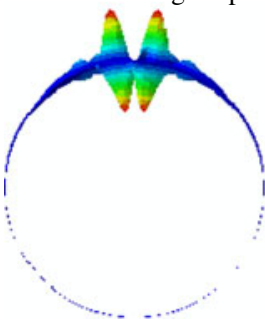

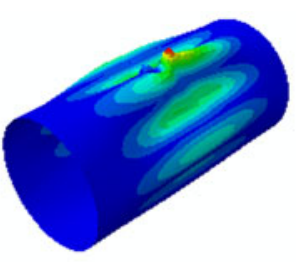

Transition buckling shapes

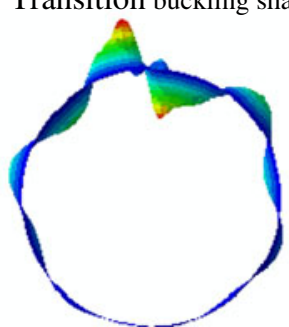

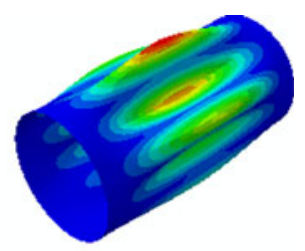

Global buckling shapes

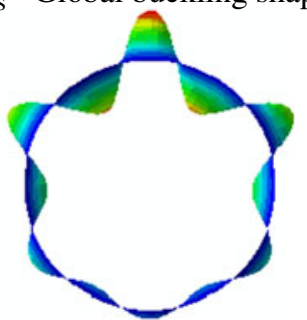

Fig. 6 a Interaction buckling curve, axial compressive load vs. pressure, of a CFRP cylindrical shell with circumferential crack at the shells mid-length at different bending moment and bending angle a $\theta=90, \mathbf{b} \theta=0$. c Typical local buckling shape of a cracked cylinder comprising a circumferential crack at $\theta=0$, i) $(L=2 \mathrm{~m}, R=$ $0.5 \mathrm{~m}$, Ply thickness $=0.125 \mathrm{~mm}$, Crack length $=0.1 \mathrm{~m}$ ) 
has an effect on both the buckling load and shape; (c) Local: in this mode buckling deformation is localized to the crack region, and the buckling load is considerably lower than the buckling load of the uncracked cylinder. Obviously, the influence of the crack on the buckling mode is easily apparent in Fig. 6 (a)-(b). It can be seen that for lower values of the axial compressive load and higher values of the external pressure $(P>0.7 p)$, the buckling is usually in the global mode. On the other side, for higher values of axial compressive load and lower levels of external pressure the buckling mode is mostly in the local mode. Depending on the bending moment, transitional buckling mode of the circumferential cracked cylindrical shell can be for the external pressure in the range of $0.68 \mathrm{Pc}<\mathrm{P}<72 \mathrm{Pc}$.

Figure 6(a)-(b) show that buckling load of the shell increases slightly when the internal pressure level increases. For the cylindrical shell with circumferential crack, the internal pressure makes stable the cylinder by elimination the local buckling at the crack region. According to Figs. 6 (a)-(b), it can be seen that the bending moment with bending angle of $\theta=0$ creates the lower buckling load than bending with angle of $\theta=90$, as expected.

Figure 7 depicts the interaction curves, axial compression $\left(R / R_{c}\right)$ vs bending angle $(\theta)$, at different pressure level for both axial crack and circumferential crack. The pressure level varies from $-0.5 \mathrm{P}_{\mathrm{c}}$ to $0.5 \mathrm{P}_{\mathrm{c}}$. It can be seen that for both axial crack and circumferential crack

a)
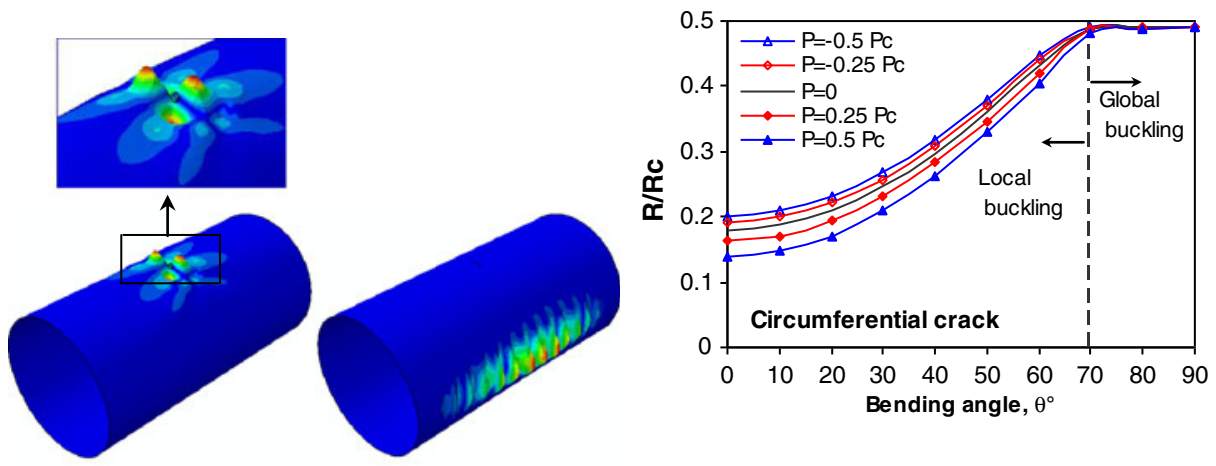

b)
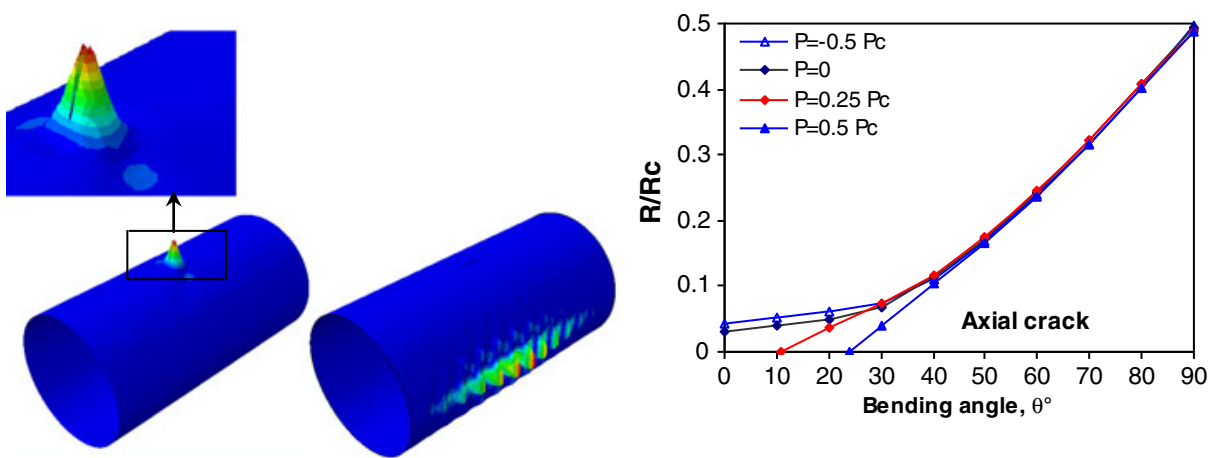

Fig. 7 a Interaction buckling curve, axial compressive load vs. bending angle, of a CFRP cylindrical shell at different pressure level at $M=0.5 \mathrm{Mc}$ a circumferential crack, b axial crack (Crack length $=0.1 \mathrm{~m}$ ) 
the external and internal pressure decreases and increases the critical buckling load, respectively. It can be deduced that the stiffening effect of internal pressure and weakening effect of external pressure are the dominant mechanisms.

Figure 7(a) shows that for shells with circumferential crack for bending angle of $\theta<70^{\circ}$ local buckling is observed and critical buckling load increased gradually as the bending angle increased. Subsequently, for bending angle of $\theta>70^{\circ}$, the critical buckling loads remain unchanged due to global buckling mode. Another observation is that for the cylindrical shells subjected to bending, pressure and axial load the global buckling shape is insensitive to the pressure level.

Figure 7(b) compares the interaction curves, axial compression $\left(R / R_{c}\right)$ vs bending angle $\theta$, of the cracked CFRP cylindrical shell with axial crack. It shows that buckling load of the shell increases gradually when the bending angle increases. It is also noteworthy that for bending angle of $\theta<90^{\circ}$ local buckling is observed and global buckling is observed just for $\theta=90$. Another observation is that for relatively high values of the bending angle the buckling is independent of the pressure in the range of pressure studied here.

Figure 8 shows the effect of bending angle and crack orientation on critical buckling load in the absence of the pressure and subject to the preloading of $0.5 \mathrm{Mc}$ and bending angle of $\theta=0^{\circ}$. For cracked cylindrical shells subject to bending with a crack oriented from the circumferential line the critical buckling load of the cylindrical shell reduce by increasing the crack angle from the circumferential line. Figure 8 shows that for $\theta<45^{\circ}$, the critical buckling curves for $a=0^{\circ}$ and $a=30^{\circ}, a=45^{\circ}$ are very close. However, when $\theta>45^{\circ}$, for the same crack size, the crack which is located on the mid-surface of the cylindrical shell, creates the lower buckling load.

Figure 9 (a)-(b) show the effect of crack size and bending moment, M/Mc, on the buckling behavior of cylindrical shells with bending angle of $\theta=90^{\circ}$ and $\theta=0^{\circ}$. Figure 9(a) shows that the buckling loads of the CFRP cylindrical shell decrease on increasing the crack size, as expected.

Figure 9(a) shows that each buckling curve is composed of two lines. Comparing Fig. 9a it can be deduced that at the beginning of buckling critical buckling load decreased

Fig. 8 Interaction buckling curves of a cylindrical shell for different crack orientation

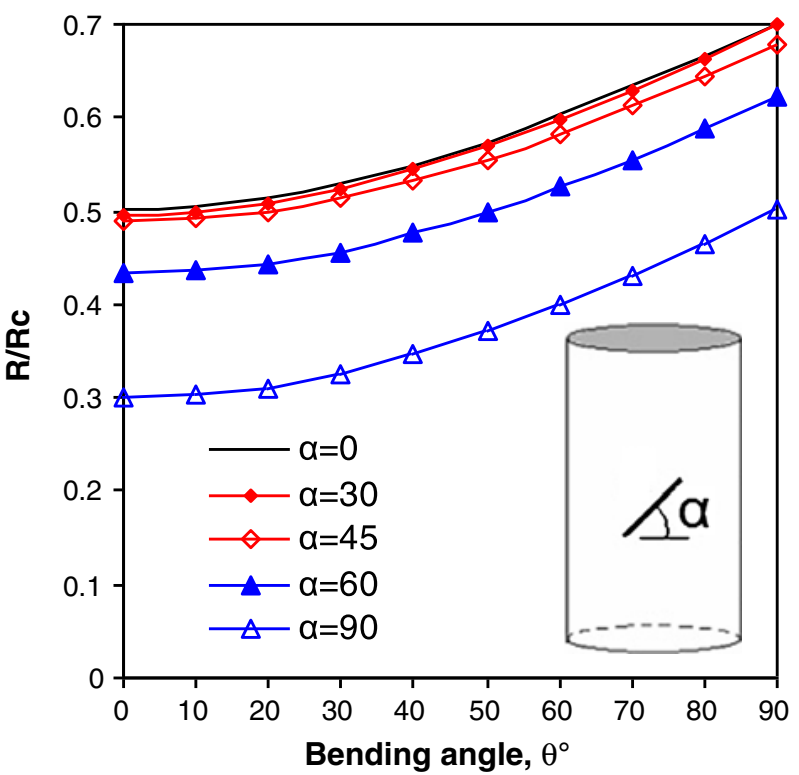


Fig. 9 Interaction buckling curves, axial compressive load vs. bending, of a cylindrical shell for different normalized crack length in different bending angle $\mathbf{a} \theta=0^{\circ}$, b $\theta=90^{\circ}$
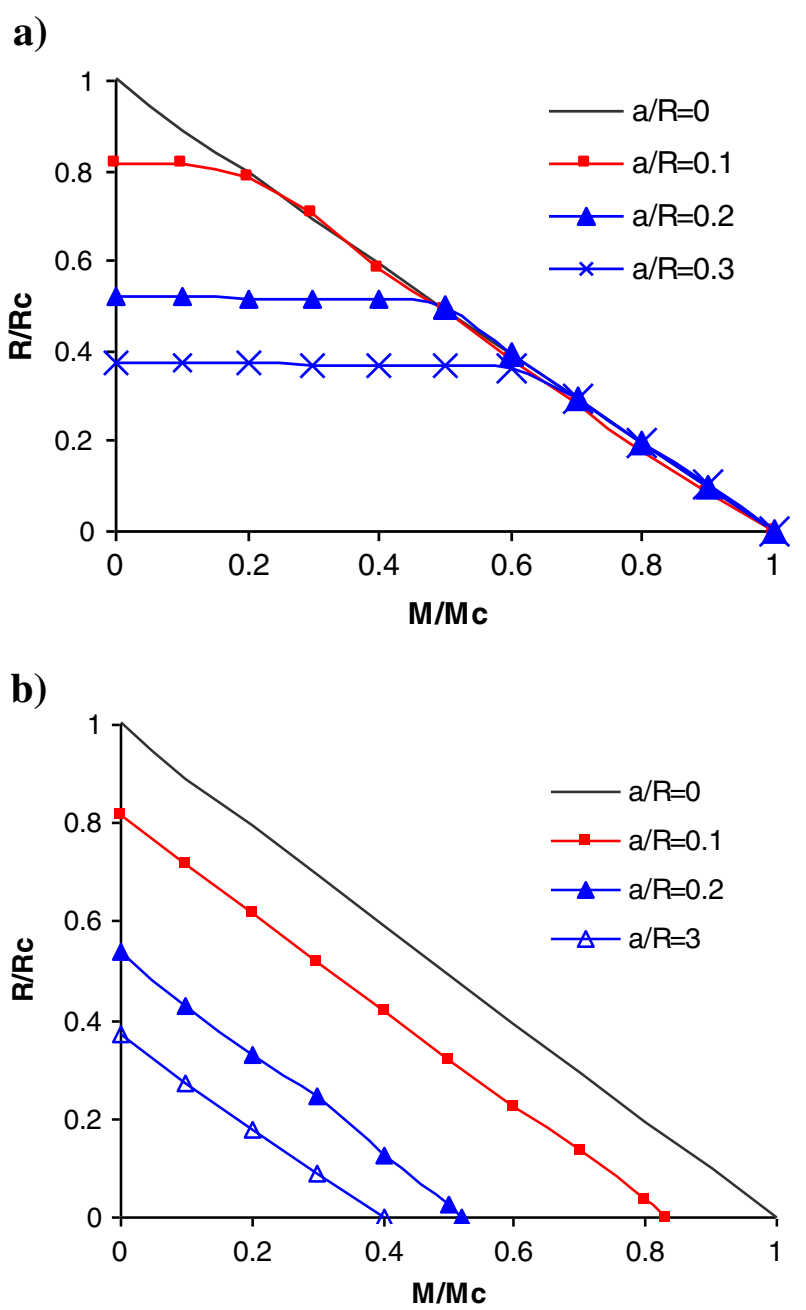

negligibly as the bending increased. Subsequently, when the bending increases further the load decreases moderately.

The effect of the crack size on the buckling mode is easily apparent. It can be seen that for lower values of the axial compressive load and higher values of the bending moment the buckling is usually in the global mode. On the other hand, for higher values of axial compressive load and lower bending moment the buckling mode is mostly in the local mode. Another observation is that increasing the crack size postpones the global buckling of the cracked cylindrical shell so that for shells with crack length of $\mathrm{a} / \mathrm{R}=0.1,0.2$ and 0.3 global buckling mode occur at bending of $\mathrm{M} / \mathrm{Mc}=0.2,0.5$ and 0.6, respectively. According to Fig. 9(a), it is clear that the crack size has no effect on buckling load of cylinder in global buckling mode.

Figure 9(b) shows the effect of crack size and bending moment, $M / M_{c}$, on the buckling behavior of cylindrical shells with bending angle of $\theta=0^{\circ}$. It can be seen that increase of crack length decreases the critical buckling load and onset of the buckling mode. Since the buckling mode of cylinder subjected to bending moment with bending angel of $\theta=0$ is locally at the crack region so the buckling curves are linear. 
In this section, the results of the buckling analysis in cylindrical shells with circumferential crack in different location along the entire length of the shells are presented. For this purpose, a circumferential crack with length of $a=100 \mathrm{~mm}$ with is created on the shells with distances from the lower edge of the shell as L0=L/2, L/3, L/6. Figure 10(a)-(b) shows that the crack location of $\mathrm{L} 0=\mathrm{L} / 2$ created the worst situation (lower buckling load), in comparison to tubes with the crack located at either $\mathrm{L} 0=\mathrm{L} / 3$ or L/6. Figure $10(\mathrm{~b})$ shows that for the cylindrical shells subjected to bending and axial load the global buckling shape is insensitive to the crack location.

\section{Concluding Remarks}

Numerical analysis carried out to study the response of CFRP cylindrical shells using the finite element method under combined loading. The interaction buckling curves of cracked cylindrical

Fig. 10 a Interaction buckling curves, axial compressive load vs. bending moment, of a cracked cylindrical shell for various position of the crack in bending angle of $\theta=0^{\circ}$ and $P=0$, b Interaction buckling curves, axial compressive load vs. bending angle, of a cracked cylindrical shell for various position of the crack in bending moment of $\mathrm{M} / \mathrm{Mc}=0.5$ and $P=0$ a)

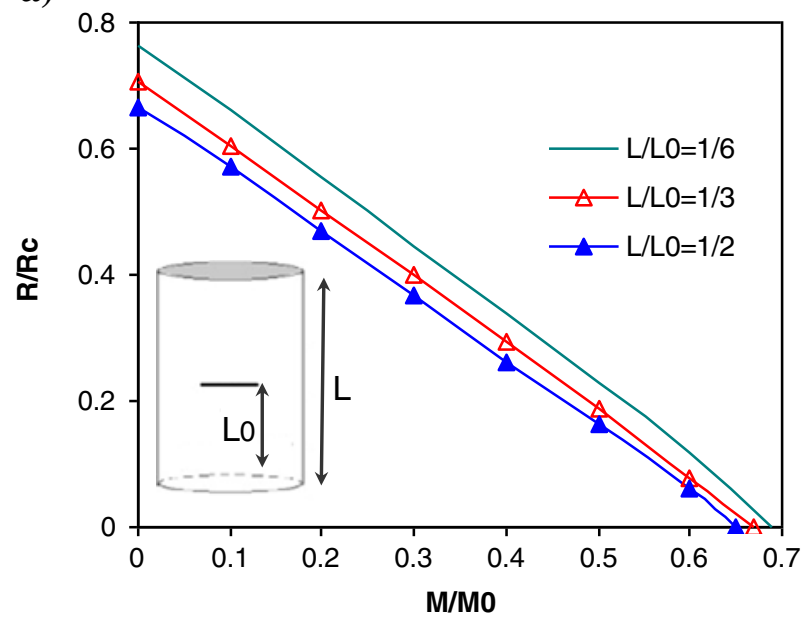

b)

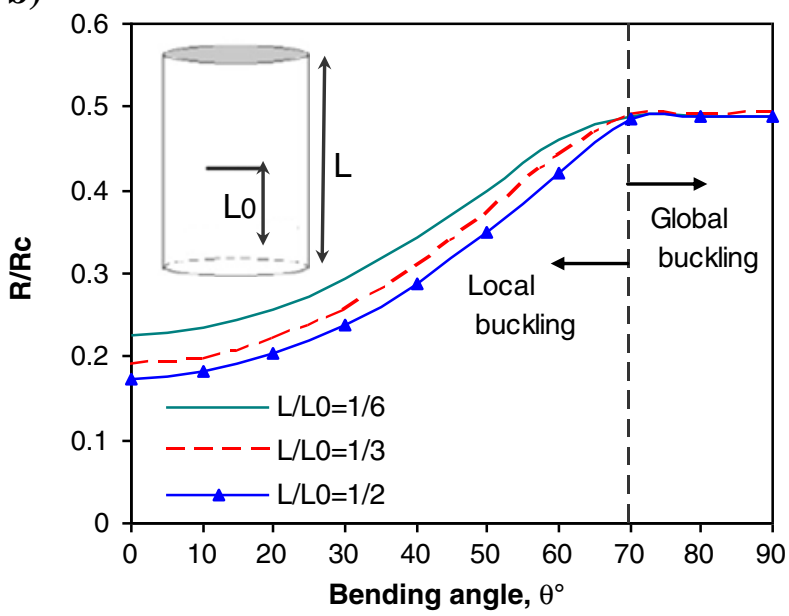


shells under different combinations of axial compression, bending, internal and external pressure are obtained. The results show that for cracked CFRP cylindrical shell subject to bending and axial compression, internal pressure increases the critical buckling load slightly and for high values of the external pressure the critical buckling loads reduce considerably. Furthermore, it can be seen that buckling load decreases with the increase in bending $(\mathrm{M} / \mathrm{Mc})$ and external pressure. Eigenvalue analysis shows that axial crack has the most detrimental effect on the buckling load of a cylindrical shell. Results shows that the buckling loads of the CFRP cylindrical shell decrease on increasing the crack size and increasing the crack size postpones the global buckling of the cracked cylindrical shell. Also, when the crack is created at the midheight, the cylinder has the minimum of the critical buckling load.

This paper shows that for lower values of the axial compressive load and higher values of the bending moment the buckling is usually in the global mode. On the other hand, for higher values of axial compressive load and lower bending moment the buckling mode is mostly in the local mode. It is shown that numerically generated interaction curves can summarize the critical buckling loads of CFRP composite shell subject to combined loading. The interaction curves should be help for coming design of cylindrical shells under complex loading conditions. Nevertheless, more investigation is necessary to set up generally applicable, right and safe guidelines for a purely computational buckling design. This study considered only the cracked cylindrical shells Therefore; it would be desired to investigate the cutout, shell-wall thickness variations and delamination. The various boundary conditions and non-uniform distribution of the applied loads can also be analyzed.

\section{References}

1. Hutchinson, J.W., Tennyson, R.C., Muggeridge, D.B.: Effect of local axisymmetric imperfection on the buckling of a cylindrical shell under axial compression. AIAA J. 9, 48-52 (1972)

2. El Naschie, M.S.: Branching solution for local buckling of a circumferentially cracked cylindrical-shell. Int. J. Mech. Sci. 16, 689-697 (1974)

3. Estekanchi, H.E., Vafai, A.: On the buckling of cylindrical shells with through cracks under axial load. Thin Wall Struct. 35, 255-274 (1999)

4. Weaver, P.M.: Design of laminated composite cylindrical shells under axial compression. Compos. Part B 31, 669-679 (2000)

5. Geier, B., Meyer-Peiening, H.R., Zimmermann, R.: On the influence of laminated stacking on buckling of composite cylindrical shells subjected to axial compression. Compos. Struct. 55, 467474 (2002)

6. Sun, G., Hansan, J.S.: Optimal design of laminated composite circular-cylindrical shells subjected to combined loads. J. Appl. Mech. 55, 136-142 (1998)

7. Diaconu, C.G., Masaki, S., Sekine, H.: Buckling characteristics and layup optimization of long laminated composite cylindrical shells subjected to combined loads using lamination parameters. Compos. Struct. 58, 423-433 (2002)

8. Meyer-Peiening, H.R., Farshad, M., Geier, B., Zimmermann, R.: Buckling loads of CFRP composite cylinders under combined axial and torsion loading-experiments and computations. Compos. Struct. 53, 427-435 (2001)

9. Sai Ram, K.S., Sreedhar, B.T.: Buckling of laminated composite shells under transverse load. Compos Struct 55, 157-168 (2002)

10. Vaziri, A., Estekanchi, H.E.: Buckling of cracked cylindrical thin shells under combined internal pressure and axial compression. Thin-Walled Struct. 44, 141-151 (2006)

11. Starnes Jr., J.H., Rose, C.A.: Nonlinear response of thin cylindrical shells with longitudinal cracks and subjected to internal pressure and axial compression loads. AIAA 97, 1144 (1997)

12. Vaziri, A.: On the buckling of cracked composite cylindrical shells under axial compression. Compos. Struct. 80, 152-158 (2007)

13. Jahromi, B.H., Vaziri, A.: Instability of cylindrical shells with single and multiple cracks under axial compression. Thin-Walled Struct. 54, 35-43 (2012) 
14. Vafai, A., Estekanchi, H.E.: A parametric finite element study of cracked plates and shells. Thin-Walled Struct. 33, 211-229 (1999)

15. Vafai, A., Javidruzi, M., Estekanchi, H.E.: Parametric instability of edge cracked plates. Thin-Walled Struct. 40, 29-44 (2002)

16. Vaziri A., Nayeb-Hashemi H., Estekanchi H.E.: Buckling of the Composite Cracked Cylindrical Shells Subjected to Axial Load ASME Conference Proceedings, 87-93 (2003)

17. Estekanchi, H.E., Vafai, A., Kheradmandnia, K.: Finite element buckling analysis of cracked cylindrical shells under torsion. Asian J. Civ. Eng. 3, 73-84 (2002)

18. Tafreshi, A.: Delamination buckling and post-buckling analysis of composite cylindrical shells subject to axial compression and external pressure. Compos. Struct. 72, 401-418 (2006)

19. Tafreshi, A., Colin, G.: Bailey Instability of imperfect composite cylindrical shells under combined loading Bailey. Compos. Struct. 80, 49-64 (2007)

20. Shariati, M., Sedighi, M., Saemi, J., Eipakchi, H.R., Allahbakhsh, H.R.: Numerical and experimental investigation on ultimate strength of cracked cylindrical shells subjected to combined loading. Mechanika 4, 12-19 (2010)

21. Huyan, X., Simitses, G.J., Tabiei, A.: Nonlinear analysis of imperfect metallic and laminated cylinders under bending loads. AIAA J. 34, 2406-2413 (1996)

22. Barut, A., Madenci, A., Britt, V.O., Starnes, J.H.: Buckling of a thin tension loaded composite plate with an inclined crack. Eng. Fract. Mech. 58, 233-248 (1997) 